\title{
HISTORIA DE LA VIDA PRIVADA ENTRE DOS SIGLOS: TESTAMENTOS DE HISPANOAMERICANAS EN CÁDIZ
}

\author{
Gloria Zarza Rondón \\ Universidad de CÁdIZ
}

\section{RESUMEN}

Presentamos en el siguiente artículo, una selección de dos testamentos de mujeres hispanoamericanas vinculadas a la élite comercial y de negocios de la ciudad de Cádiz. Junto a las disposiciones, sus correspondientes particiones de bienes, a partir de las cuales hemos intentado acercarnos al mundo en que se desenvolvieron estas mujeres, reconstruyendo una imagen de la vida cotidiana y de las actitudes mentales ante un acontecimiento tan trascendental como es la propia muerte. Para ello hemos hecho uso de las fuentes que obran en el Archivo Histórico Provincial de Cádiz, uno de los más importantes del país, y que nos hacen partícipes de lo cotidiano, de la vida, y muy especialmente del tránsito final, que convive con el hombre y la mujer, condicionando su vida y su quehacer diario de manera fácilmente perceptible.

PALABRAS CLAVE: Protocolo notarial, vida cotidiana, exequias, burguesía, Carrera de Indias.

\section{ABSTRACT}

Let's sense beforehand in the following article, a selection of two testaments of Spanish-American women linked to the commercial and business elite of the city of 
Cadiz, with his corresponding partitions of goods, from which we have tried to approach the world in which they were unrolled and to reconstruct an image of the daily life and of the mental attitudes before an event as transcendental as it is the own death. For it we have used the sources that act in the Historical Provincial File of Cadiz, one of the most important of the country, and that there do to us participants of the daily thing, of the life, and very specially of the final traffic, which coexists with the man, determining his life and his daily occupation of an easily perceptible way.

KEY WORDS: Notarial protocol, daily life, obsequies, middle class, Career of The Indies.

\section{INTRODUCCIÓN}

En primer lugar comenzaremos señalando, que el artículo que sigue forma parte de una investigación más amplia titulada Cádiz, Puerto y Puerta de América. Presencia de hispanoamericanos en Cádiz entre 1765 y 1840 ${ }^{1}$. Para esta investigación, hemos seleccionado dos disposiciones testamentarias que, a nuestro juicio reflejan con mayor claridad las actitudes y sentimientos que afloraban ante un acontecimiento tan trascendental en la vida de toda persona como es su propia muerte. Analizaremos así, como entre el siglo XVIII y XIX, el ritual barroco vinculado al fallecimiento, va evolucionando y vaciándose de contenido, hasta desembocar en un mero hecho protocolario, que la mayoría de las veces queda en manos de los albaceas.

Junto a los dos testamentos, sus oportunas particiones de bienes, que nos ofrecen una idea del transcurrir de la vida diaria de estas dos mujeres, quienes abriéndonos las puertas de su intimidad nos han permitido profundizar en la vida privada y el quehacer cotidiano en que se desenvolvieron.

El primero de los testamentos corresponde a una descendiente de la oligarquía criolla hispanoamericana: Manuela Bustillo Saenz Rico, vinculada a una de las familias más influyentes en Centroamérica a fines del XVIII y comienzos del XIX: los Aycinena, en cuyo poder se mantuvo la producción de añil, ganado, textil y plata hasta mediados

1 ZARZA RONDÓN, G.: Tesis Doctoral (En prensa) Dichas fechas no han sido elegidas al azar. La primera de ellas, 1765, marca el inicio de la ruptura del monopolio gaditano en el comercio con Indias tras la promulgación del Decreto de Ley de Libre Comercio el 16 de octubre. A partir de esta fecha, quedarían habilitados nueve puertos peninsulares para comerciar con las colonias españolas en América: Cádiz, Sevilla, Málaga, Barcelona, Santander, Alicante, Cartagena, Gijón y Coruña. En 1778, la Real Cédula y Reglamento de 12 de octubre de 1778, ampliará el decreto anterior, ratificando y extendiendo el comercio "libre y protegido" entre 13 puertos peninsulares y 24 americanos. Cabe destacar, que como si se tratara del redescubrimiento de una nueva América, esta declaración de libertad comercial coincidió con las efemérides del primer Descubrimiento. (Fuente) CORONAS, S. A: "La reforma del comercio indiano a la luz de la documentación conservada en el Archivo de Campomanes (1762- 1778)", en Espíritu Ilustrado y liberación del tráfico comercial con Indias.

La segunda fecha, 1840, la hemos seleccionado como representativa del completo declive comercial de la ciudad de Cádiz con Hispanoamérica, que a partir de 1831, con la supresión de la franquicia del puerto gaditano, continuaría su camino descendente en cuanto a tráfico comercial con América se refiere. (Nota aclaratoria de la autora). 
de siglo. Casada con Pedro de Aycinena e Irigoyen, hermano del primer marqués de Aycinena radicado en Guatemala.

En cuanto a la segunda disposición, pertenece a una representante de la nobleza vinculada al comercio de la Carrera de Indias: María Osoria Astrudi y Roelas, Marquesa de Casares, viuda de José de Peralta Manrique de Lara, cuya partición de bienes, supone el ejemplo de un cuantioso patrimonio en propiedades inmobiliarias, fincas y demás bienes muebles, además del capital efectivo y las alhajas con las que cuenta.

En relación a los testamentos ${ }^{2}$, señalaremos que su uso se extendió durante el Antiguo Régimen a todas las clases sociales, en una sociedad marcadamente sacralizada y jerarquizada que se preocupó de prolongar su status aún después de la muerte, y siendo el sentimiento de proximidad a ella la razón que les impulsaba a testar ${ }^{3}$.

Un elemento que debemos tener en cuenta, es la elevada tasa de difusión de esta práctica entre las mujeres y la participación proporcionada por parte de todos los grupos sociales ${ }^{4}$, aportándonos un valor incalculable como fuente de la cotidianeidad y depósito de gestos y de prácticas colectivos.

Respecto a la estructura de estas dos disposiciones: da comienzo con la invocación a Dios Todopoderoso, seguida de la presentación de la otorgante y sus progenitores. Seguidamente nos informa de su origen geográfico y su estado civil. Continúan las invocaciones a la Santísima Trinidad y el papel de los intercesores para la obtención de la misericordia, donde el valimiento más eficaz es el de la Virgen, quien como madre del Redentor aparece como la abogada e intercesora por excelencia ${ }^{5}$. Tras las disposiciones piadosas, referidas al tipo de exequias religiosas, y a la forma y modo del funeral y entierro, tiene lugar la descripción de los hechos más trascendentales en la vida de estas mujeres; es decir, la alusión al matrimonio: cuándo, dónde y con quién se efectuó, así como los hijos, habidos o no, del enlace. A continuación, encontramos las cláusulas relativas a los diferentes legados que cada testadora realiza. Finalmente, la fecha, así como la firma de la otorgante y los testigos, ultiman la disposición.

En lo que se refiere a la firma de las testadoras, índice utilizado en otras investigaciones para medir el grado de instrucción, comprobamos, que efectivamente,

2 DEL CERRO BOHÓRQUEZ, Ma Paz: Mujer, herencia y patrimonio en la sociedad rural gaditana del Antiguo Régimen. Alcalá de los Gazules, Chiclana de la Frontera y Medina Sidonia. (1670-1750). Servicio de Publicaciones de la Universidad de Cádiz. Cádiz, 2005. Dicha obra es de obligada consulta en nuestra investigación. En ella se hace hincapié en la importancia que revisten los testamentos como herramienta idónea que nos aproxima al estudio de las actitudes colectivas y a la historia de las mentalidades. A través de los mismos nos acercamos a la vida cotidiana, a los niveles socioeconómicos de los otorgantes, siendo fundamental para el estudio de la historia social y de las mentalidades.

3 ZARZA RONDÓN, G.: Cádiz, Puerto y Puerta de América... A lo largo de nuestra investigación hemos constatado, que hay diversas razones para otorgar un testamento: la coyuntura de un viaje próximo, una enfermedad inesperada, o la prolongación de la misma, y por último, la ancianidad. (Nota de la autora).

También corrobora esta aseveración la obra de PANIAGUA PÉREZ, J.: Morir en Cádiz (1650- 1859). La vida y la muerte de las gentes de los obispados de Astorga y León en Cádiz, así como de Oviedo en la provincia de León. Editorial Lobo Sapiens. León, 2009.

4 DE LA PASCUA, M ${ }^{\mathrm{a}}$ J.: Vivir la muerte en el Cádiz del setecientos, Fundación Municipal de Cultura. Exmo. Ayuntamiento de Cádiz, 1990 p. 66.

5 Ibídem, op. cit. 112. 
las dos otorgantes firman sus testamentos ${ }^{6}$. Este hecho podría ser consecuencia de que las mujeres que hemos seleccionado en nuestra investigación, pertenecen a familias burguesas, con maridos difuntos, vinculados a la Carrera de Indias y al mundo de la élite comercial, y por tanto, habrían sido instruidas para saber leer y escribir en su nivel más elemental.

Así pues, hemos elegido estos dos testamentos, por ser los que con mayor detalle reflejan cómo discurría la vida de este sector de la población. Sin duda, otra de las razones que nos han llevado a optar por ellos es el nivel económico que poseían, y que puede comprobarse en las particiones de bienes analizadas, permitiéndonos conocer con más precisión los bienes que conformaban las grandes casas de la burguesía de negocios. En definitiva, eran mujeres que tenían la posibilidad de legar en sus testamentos auténticas fortunas, en detrimento de aquellas, que habiendo subsistido en una vida llena de precariedades, optaban por otorgar testamento para asegurarse un mínimo de dignidad y bienestar en la otra vida.

Sin más preámbulo, pasemos a analizar más detenidamente a cada una de ellas:

\section{SELECCIÓN DE DOS TESTAMENTOS DE MUJERES HISPANOAMERICANAS RESIDENTES EN CÁDIZ}

\section{1.- Disposición testamentaria de Manuela Bustillo y Sáenz Rico7}

La otorgante, oriunda de la ciudad de Veracruz es viuda de Pedro de Aycinena ${ }^{8}$.

Se encomienda muy especialmente a la Reina de los Ángeles, al Ángel de la Guarda y a toda la Corte Celestial.

En lo relativo al entierro y funeral, pide ser amortajada con el hábito de nuestro seráfico Padre San Francisco ${ }^{9}$, y enterrada en el convento de San Francisco Casa Grande. En cuanto al número de misas que deberán oficiarse por su alma, estas ascienden a nada más y nada menos que 9000 misas rezadas, pagada cada una de ellas a 5 reales de vellón, lo que suma la cantidad nada desdeñable de 45.000 reales, o lo que es lo mismo, unos 2.250 pesos fuertes que deberán ser repartidos entre la

6 ZARZA RONDÓn, G.: Cádiz, Puerto y Puerta... en nuestra investigación hemos corroborado que cuando el otorgante no era el que estampaba su rúbrica, aparecen distintas razones anotadas someramente por el escribano en cuestión. Entre las causas que impedían a los testadores firmar existían: el sencillo, no sabe, o no firmó porque dijo no saber escribir; o bien, no firmó debido a que se lo impedía su enfermedad, o, el testador dice no poder firmar por no poder levantarse debido a la gravedad de su enfermedad.

7 AHPC: Sección de Protocolos Notariales. Libro 3856. Año de 1788.

$8 \mathrm{http} / / / \mathrm{www}$.euskomedia.org/aunamendi/: Los ayzinena o aycinena fueron una de las familias más influyentes de Centroamérica a finales del siglo XVIII y comienzos del XIX, controlando la mayor parte de la producción de añil, ganado, plata y textiles. Originarios de Navarra de Berroeta (Baztán), a comienzos del siglo XVII, D. Juan Miguel de Aycinena y Alzuade, señor de la casa Joannes de Aycinena, fue diputado por Ciga en las Juntas Generales del valle durante 1729,1732 y 1735. Casado con Antonia Irigoyen tuvo cinco hijos, de los cuales Pedro y Juan Fermín pasaron a América. Pedro de Aycinena vivió en Veracruz y volvió a morir en Ciga donde fundó una obra pía con 800 pesos de capital.

9 GONZÁLEZ CRUZ, D.: Religiosidad y ritual de la muerte en la Huelva del siglo de la Ilustración. Colección Investigación. Excelentísima Diputación de Huelva. Huelva 1993. El autor aclara en su obra que, el hábito franciscano fue elegido mayoritariamente en casi toda la centuria del XVIII, vinculados a la humildad, la pobreza evangélica y carisma de estos "observantísimos padres". La devoción a San Francisco y a su orden religiosa fue en aumento a lo largo del siglo XVIII, como lo demuestra el que la elección del hábito seráfico se incrementase alcanzando su cénit en el quinquenio 1785 a 1789. p. 206. 
colecturía de la iglesia catedral, y las iglesias y sacerdotes encargados de celebrar los oficios $^{10}$.

A continuación, la testadora informa que contrajo matrimonio en Veracruz, el 23 de julio de 1753, hace 35 años, con el citado Pedro de Aycinena. La dote ascendía a 20.000 pesos fuertes, entre dinero efectivo y alhajas. Su esposo le regaló la cantidad de 2.000 pesos fuertes, además de las arras que aportó al enlace, que consistieron en 24.000 pesos fuertes.

Del matrimonio nació una hija, única descendiente de la testadora: María Dolores de Aycinena y Bustillo, de 16 años.

El esposo, murió en Cádiz en 1784; un año después, la otorgante contrajo segundas nupcias con José Javier de Goenaga, comerciante de la Carrera de Indias. Al matrimonio, la contrayente aportó como dote 30.000 pesos fuertes, y el cónyuge, en calidad de arras: 4.000 pesos. De este enlace no hubo descendencia.

En referencia a las exequias convenidas, lega diferentes cantidades a religiosas tanto de Cádiz y provincia, como de México, de donde es natural. Concede 500 pesos al convento de franciscanos descalzos de Cádiz. Otros 500 pesos para el convento de religiosas del Puerto de Santa María, encargándoles que oficien una misa cantada y doce rezadas ante la imagen de la Virgen de los Dolores. De igual forma, se entregarán 500 pesos más al convento de religiosas la carmelitas descalzas de la villa de Alcalá de los Gazules, y que celebren una misa cantada y ocho rezadas por su alma ante la imagen de Nuestra Señora de Guadalupe, a quien tiene especial devoción; otros 500 al convento de religiosas de la Purísima Concepción de Jerez de la Frontera, donde deberán oficiarse una misa cantada y 12 rezadas en honor a la preciosa sangre que derramó Jesucristo Nuestro Redentor en su Pasión; y 1.000 pesos más repartidos a las fieles más necesitadas del convento de religiosas capuchinas, y religiosas del Corpus Christi situado en la ciudad de México. Igualmente, asigna para dotes de religiosas gaditanas, la cantidad de 1.000 pesos fuertes; igual cuantía para el Hospital de Pobres Mujeres enfermas con vocación de Nuestra Señora del Carmen de Cádiz; y otros 1.000 pesos, a repartir por sus albaceas entre las pobres vergonzantes ${ }^{11}$ de la ciudad. Junto a ello, también se hace responsable de las criadas de su hogar, a quienes deja, tras su

10 La pompa funeral distinta del modo y orden prevenidos por el Ritual Romano, y permitida por los cánones, y por las leyes, son más efecto o del honor de los vivos parientes o amigos del difunto, o de su vanidad, sobre lo cual, hay leyes, que si bien toleran cierto grado, prohíben otros. Nada sirve a los difuntos esta pompa, pero sí los sufragios, que también excitan la piedad de los vivos al mismo tiempo que les recuerda de los Novíssimos". Memorial de los curas párrocos de Cádiz. A. M. C. Sección Actas Capitulares. Cabildo de 24 de abril de 1802. fol. 208 v. DE LA PASCUA, Ma José, señala en su obra Vivir la muerte..., que la Iglesia era consciente de este desarrollo de las pompas, fruto de la vanidad humana más que del deseo de albar a Dios, pero lo aceptaba como un mal menor al decir de los párrocos gaditanos. Quizá por ello, porque las creencias que sustentaban estas ceremonias (consuelo para los muertos, seria advertencia para los vivos que lo contemplan) habían quedado relegadas u ocultas por la significación social de esta representación, a los gaditanos de finales del Setecientos no parece importarles demasiado la sustitución de este escenario religioso por otro más profano pero menos vistoso. p. 139. Igualmente, la autora señala que el final del siglo XVIII gaditano, nos ofrece la posibilidad de captar la descomposición del teatro barroco funerario de los siglos anteriores. p. 138. También en GÓMEZ NAVARRO, S.: El sentido de la muerte y la religiosidad a través de la documentación notarial cordobesa (1790-1814). I. Análisis y estudio de los testamentos. Granada, 1985, p. 94, se señala la rapidez con la cláusula de los funerales va perdiendo contenido en el testamento de finales del XVIII y comienzos del XIX.

11 Persona que por su anterior status y obligaciones no puede pedir limosna de puerta en puerta, y lo hace de modo que sea con el mayor secreto posible. En la época trabajada encontramos dos modelos de pobres; el pobre vergonzante ya señalado, y el pobre de solemnidad, grupos de marginados entre los que abundaban las viudas y enfermos que se veían obligados a vivir de la mendicidad.(Nota de la autora). 
fallecimiento, cantidades de dinero proporcionales al mérito, trabajo y circunstancias de cada una de ellas. Con las mujeres de su familia, lleva a cabo el mismo procedimiento. A cada una de sus cinco hermanas: Juana Dolores, Ignacia, María Josefa, Rosa e Isabel, adjudica 2.000 pesos fuertes para que lo empleen en lo que más les convenga; al igual que a su sobrina, Ignacia Ruanova, vecina de la ciudad de Veracruz. Por último, lega 1.000 pesos fuertes a José Algarín, residente en la ciudad de Tabasco, para que le sirva de alivio y sustento de sus hijas, que son ahijadas de la testadora. Deducimos así, que a la responsabilidad manifiesta que refleja el testamento, se une la profunda protección al elemento femenino de la familia, pues la testadora se afana en asegurar un mínimo sustento a todas las mujeres que han formado parte de su vida; e igualmente preferencia por auxiliar a los conventos femeninos.

Continúa el documento nombrando a los albaceas testamentarios: en primer lugar, su esposo, José Javier de Goenaga, a quien deja en herencia la quinta parte de sus bienes por el gran afecto que le profesa; y como segundo legatario, a su sobrino: Fermín de Elizalde y Aycinena.

Como heredera única y universal, su hija María Dolores, pero durante la minoría de edad, será el marido quien administre todos los bienes.

En un segundo documento, se lleva a cabo el Inventario de bienes y Cuentas de la testamentaría ${ }^{12}$ de Manuela Bustillo y Sáenz Rico:

1.- Bienes en capital efectivo, género y vales reales:

- el capital efectivo y vales reales que asciende a: 2.128 .588 reales de plata (142.000 pesos fuertes aproximadamente).

- el importe de dos escrituras de riesgo, con valor cada una de ellas de 9.120 pesos fuertes, que Antonio de Vega había otorgado a favor de la testadora en virtud de dos navíos que partieron desde el puerto del Callao al de Cádiz, nombrados: El Ventura, y La Rosa.

- un pagaré que ascendía a 5.050 pesos fuertes a cargo de Francisco Páez de la Cadena, vecino de San Lúcar de Barrameda.

- otro pagaré de 3.250 pesos a cargo de Javier Ignacio de Amenábar.

- cobranzas y liquidaciones hechas a la muerte de su primer esposo, 2.795 pesos fuertes.

- seis mulas para coches, 400 pesos fuertes.

2.- Bienes en plata labrada, alhajas y muebles:

- en plata labrada que quedó a la muerte de su primer marido, tasada por Vicente Faxardo, con un peso aproximado de $746 \operatorname{marcos}^{13}$ y que ascendía a 5.950 pesos fuertes.

- en alhajas de oro, 406 pesos fuertes.

- por un puñal guarnecido en plata antigua y puño de oro: 200 pesos fuertes.

- un par de pendientes, una medalla y un reloj, todo de brillantes y rosas: 2.218 pesos fuertes.

12 AHPC: Sección de Protocolos Notariales. Libro 3856. Año de 1788.

13 www. Curiosidadesdelaciencia.com: Medida de peso que durante los siglos XVII y XVIII ascendía a 230 gramos cada marco. 
- dos tocadores maquetados en caoba tasado en 200 reales de vellón (10 pesos fuertes) cada uno.

- dos mesitas doradas con piedras de jaspe, 100 pesos fuertes cada una.

- dos vírgenes grandes de Guadalupe con los marcos dorados, compradas a

Tomás Daysenberg, 456 pesos fuertes cada una.

- 12 sillas de caoba ${ }^{14}$ con brazos de asientos de paja, 1.192 pesos fuertes.

- 24 sillas de haya, pintadas, 217 pesos fuertes.

- cuatro docenas de sillas ordinarias con asiento de paja, grandes y chicas, con un valor de 95 pesos fuertes.

- una mesa grande de caoba, con dos cabeceras para el comedor, 520 pesos.

- una frasquera vacía, con sus frascos de cristal y algunos juguetes, 446 pesos fuertes.

- una colgadura de cama, una colcha y dos cortinas de tela Damasco Carmen, 396 pesos.

- un reloj de pared completo, 60 pesos fuertes.

- cinco camas de caoba con sus cabeceras, 1.934 pesos fuertes.

- una cómoda de caoba con su escribanía, 917 pesos fuertes.

- dos cómodas pequeñas de caoba para la alcoba, 800 pesos.

- dos mesas de caoba para juego, 956 pesos.

\section{2.- Disposición Testamentaria de María Osoria Astraudi y Roelas ${ }^{15}$ :}

El segundo testamento analizado es el de María Osoria Astraudi y Roelas, Marquesa de Casares. Aunque no es oriunda del continente americano sino del reino de Aragón, refiere en su testamento haber vivido desde su más tierna infancia en Arequipa, Virreinato del Perú, de donde si fue natural su difunto esposo: José de Peralta Manrique de Lara, Marqués de Casares, electo Virrey del Nuevo Reino de Granada, Jefe de escuadra de la Real Armada española y Gentil Hombre de Cámara de S. M.

Otorga su testamento en 1810, quince años después del fallecimiento de su marido en la ciudad de Cádiz. Puesto que también contamos con la disposición de su esposo ${ }^{16}$, confirmamos la presencia de su cónyuge como la principal albacea del difunto,

14 ZARZA RONDÓN, G.: Cádiz, Puerto y Puerta... (Tesis Doctoral. En prensa). Constatamos en nuestra investigación la presencia de la caoba en la mayoría de las particiones de bienes analizadas. Es por tanto una de las maderas nobles más cotizadas y utilizadas en el mobiliario doméstico de la burguesía de la época.

15 ARCHIVO HISTÓRICO PROVINCIAL DE CÁDIZ, en adelante, AHPC. Sección Protocolos Notariales de Cádiz. Libro 430. Año de 1810.

16 ZARZA RONDÓN, G.: Cádiz, Puerto y Puerta de América, la presencia de hispanoamericanos en la ciudad entre 1765 y 1840 (Tesis Doctoral. En prensa). AHPC. Sección de Protocolos Notariales. Libro 4546. Año de 1796. Habiendo analizado la disposición y autos de testamentaría del marqués, constatamos que la fortuna ascendía a: 42.067 pesos fuertes, en dinero efectivo y en vales reales; en negocios y dependencias contaba con la cantidad de 34.853 pesos fuertes y dos reales de plata; en censos redimibles, 13.341 pesos distribuidos en diferentes inmuebles y tierras de la ciudad de Cádiz y los alrededores de Granada; 1.650 pesos en plata labrada; y 1570 pesos en muebles, ropa de uso y libros. En total, el caudal mortuorio se elevaba a más de 93.000 pesos fuertes, a los que debemos sumar la cantidad pagada por el entierro y funeral del marqués, 1067 pesos, y los 6000 pesos con que dotó a su esposa antes del matrimonio. De todo ello, deducimos una fortuna de cien mil pesos fuertes. A esta cifra, incluimos, el caudal de bienes que dice poseer en América, distribuidos en tierras y haciendas, así como la cantidad de 7655 pesos fuertes invertidos en negocios comerciales en el Puerto del Callao. 
poniéndose de relieve el papel fundamental que jugará la marquesa en la distribución real de los bienes legados por el fallecido. De hecho, es uno de los elementos que más nos ha llamado la atención: la capacidad decisoria y la autoridad con la que nuestra protagonista dejará todo distribuido, y mejorado ${ }^{17}$ entre su descendencia, asegurando la continuidad del título del marquesado en su hijo varón, a cuyo favor mantiene diferentes pleitos para que lo hagan beneficiario de una serie de mayorazgos. Del mismo modo, intenta garantizar el bienestar de sus hijas, entre ellas a María Teresa, la única que, hasta el momento, estaba casada con Juan Antonio Fernández Alvarado, II Marqués de Tabalosos ${ }^{18}$, y a la que se le asignó una cuantiosa dote que consistía en: 3.500 pesos fuertes, numerosas alhajas de brillantes, broches dorados en forma de mariposa, dos hilos de perlas y una sortija de diamantes; dos docenas de cubiertos de plata y una mantilla bordada en oro.

17 Ibídem, AHPC. Sección Protocolos Notariales de Cádiz. Libro 430. Año de 1810.

A lo largo del documento comprobamos como la testadora ha emprendido diferentes litigios y pleitos para hacer valer los derechos de sus hijos, tanto del varón como de las mujeres, sobre todos aquellos bienes que en América, y en España le pertenecen por herencia paterna: desde mayorazgos, hasta la reclamación de dotes para sus hijas, y propiedades en la ciudad de Arequipa. Del mismo modo, desde el fallecimiento de su marido, ha aumentado el dinero efectivo dejado por el marqués, la cantidad de plata labrada, y las propiedades inmobiliarias pertenecientes al marquesado de Casares.

18 Revista de Genealogía, Nobleza y Armas. Año IV. Septiembre- octubre, 1956. n 18. Madrid: el segundo marqués de Tabalosos fue Juan Antonio Fernández de Alvarado y Lezo, nacido en Zamora el 26 de septiembre de 1776. El 3 de Julio de 1781 tomaba posesión del título, al que luego se añadiría los de Chancao y Cartago en la lejana Lima.

Por Real Cédula dada en Aranjuez el 15 de Abril de 1805, Carlos IV había despachado favorablemente su licencia para contraer matrimonio con la que fue su esposa: María Teresa de Peralta y Astraudi.

El 7 de Enero de 1808, su suegra, la Marquesa viuda de Casares, solicitaba al Rey en nombre suyo, desde Granada, la sucesión del marquesado de Tabalosos, a favor de su hija, María Teresa, esposa del marqués. Parece que finalmente no lo logró. El 23 de enero de 1811, a los cinco años de haber contraído matrimonio por poderes, su mujer, cansada de esperarle, reclamaba al Rey desde Cádiz, en un pintoresco documento, la presencia de su esposo, cuya resistencia obstinada tomaba a esas alturas caracteres de franca rebeldía. Ynerte y pasibo, a una real orden de diciembre de 1807 que le había ordenado volver a la Península, el II Marqués de Tabalosos se mantenía en el Callao, en su estado de indiferencia con sacrificio de la libertad de la exponente, usando todos los resortes imaginables para justificar la postergación de su partida, que finalmente fue decretada por el monarca en forma perentoria. Por determinación regia se le ordenó al vicesoberano lo embarcase en el primer navío de guerra que zarpara a España.

Sirvió en la Marina más de treinta años, siendo único Ayudante de la Capitanía del Puerto del Callao. Fue luego destinado a la Embajada de Nápoles, por Real orden de 11 de Octubre de 1817, de la que pasó a la de París.

En ocasión que hacía un viaje a la corte de España, le sorprendió la muerte en Anzánigo (Huesca) e 31 de Julio de 1833.

Archivo Central de Marina Álvaro de Bazán. Viso del Marqués. Expediente personal de don Juan Antonio de Alvarado y Lezo, Marqués de Tabalosos. No resistimos la tentación de referir parte del pensamiento que, a modo de arenga, la esposa, María Teresa de Peralta y Astraudi encabeza su memorial al Monarca: Que quando los hombres se colocan en un punto excéntrico al Imperio de las Leyes, de la Religión y de la Política. Quando arrebatados del torrente de las pasiones son el juguete de ellas y quando separados a una inmensa distancia son débiles los impulsos parciales, se ha.ce preciso que la mano fuerte del Gobierno responga a cada cual en su lugar, le haga respetar las virtudes sociales, de cuyo ejercicio pende la armonía y tranquilidad de las Naciones..., pp. 637- 638. 
En el apartado del ritual funerario, la otorgante se encomienda a la Santísima Madre de los Dolores ${ }^{19}$, con cuyo hábito desea ser amortajada ${ }^{20}$, y enterrada en el cementerio público de San José ${ }^{21}$ sin nicho ni pompa alguna. Respecto a la advocación particular de la otorgante, la Virgen de los Dolores, no es extraña dada la enorme supremacía del culto mariano en la España del siglo XVIII y su atomización en distintas advocaciones. En Cádiz, las cofradías del Carmen, Rosario, Divina Pastora y Nuestra Señora de los Dolores, tenían una presencia notable, y así se pone de manifiesto en las disposiciones testamentarias analizadas ${ }^{22}$.

En relación a las exequias estipuladas, pide que por su alma se oficien las misas que sus albaceas tengan a bien designar, pero llevadas a cabo en el convento de los carmelitas descalzos de Cádiz, uno de los lugares más demandados por los testadores de niveles medio y alto ${ }^{23}$, y que cada una de ellas sea pagadas al mayor estipendio. ${ }^{24}$ Hemos de destacar, que la elección de una determinada iglesia o convento como lugar de enterramiento nos sirve para ir adentrándonos en el mundo de las devociones, de los miedos, de las creencias, de la fe, y en definitiva de las actitudes ante la muerte de nuestras testadoras. En nuestra ciudad, constatamos una primacía del convento

19 http://www.cadizcofrade.net/historia/servitasbahia.htm: La Orden Seglar de los Siervos de María Santísima de los Dolores toma un especial impulso en España en el siglo XVIII. Cádiz, una de las ciudades de mayor crecimiento en el siglo XVIII merced a la cabecera del comercio de Indias, no iba a ser una excepción. Así, la orden se establece en la ciudad en 1727 bajo el impulso del obispo Lorenzo Armengual de la Mota. Este obispo de origen malagueño funda y manda construir la parroquia de San Lorenzo mártir donde queda establecida la orden. A partir de aquí la orden se expande con fuerza por la ciudad, construyendo en pocos años capilla propia anexa al templo de San Lorenzo.

20 PANIAGUA PÉREZ, J.: Morir en Cádiz (1650-1850). La vida y la muerte de las gentes de los obispados de Astorga y León en Cádiz, así como de Oviedo en la provincia de León. Ediciones Lobo Sapiens. León, 2009 , p. 273. El autor señala que una de las disposiciones testamentarias habituales era la del hábito del difunto. En este sentido, en Cádiz, como en otras muchas localidades de España, el de San Francisco en sus distintas versiones parece que no tuvo competencia, además de ser el que mejor se asociaba a la humildad y la pobreza con que muchos testadores querían aparecer en su aspecto físico ante la muerte. En Cádiz, existían tres conventos de las diferentes ramas franciscanas: el de los observantes, en la Casa Grande de San Francisco; el de Descalzos o de San Diego; y el de Santa Catalina de Capuchinos. En el mismo sentido, la obra de SOLÉ, P. A.: La iglesia gaditana en el siglo XVIII, Servicio de Publicaciones de la Universidad de Cádiz. 1994, p. 93, señala que en la ciudad de dio un predominio de los franciscanos, sumando bajo esta misma denominación a los descalzos S. Pedro de Alcántara; les seguían los mercedarios y capuchinos con cifras muy similares entre sí, y a niveles algo más inferiores, dominicos, hospitalarios y agustinos, con un cierto equilibrio entre las tres órdenes.

21 DE LA PASCUA, M ${ }^{\mathrm{a}}$ J.: Vivir la muerte en el Cádiz del setecientos, Fundación Municipal de Cultura. Exmo. Ayuntamiento de Cádiz, 1990 p. 153: Recordemos la Real Cédula de 3 de Abril de 1787, donde se prohibían a partir de entonces los enterramientos intramuros. No obstante, hemos de destacar, que en Cádiz, dichas prohibiciones habían caído en saco roto, bien por la inercia del propio Ayuntamiento, bien por la falta de interés del cabildo eclesiástico o por la misma oposición de los fieles. A partir de 1800, cuando comience a extenderse en Cádiz la epidemia de fiebre amarilla, comenzarían a cumplirse sin demora, ante la urgencia de la situación, las órdenes de la Real Cédula. Fue destinado como cementerio común el de la Parroquia de San José, extramuros de la ciudad, al que, dada su pequeñez, hubo que añadir un pedazo de terreno continuo. 22 ZARZA RONDÓN, G.: Cádiz, Puerto y Puerta de América, la presencia de hispanoamericanos en la ciudad entre 1765 y 1840 (Tesis Doctoral. En prensa).

23 Ibídem. Hemos comprobado a lo largo de nuestra investigación que la elección de los lugares de enterramiento y culto tienen su reflejo dentro de la jerarquía social de la época. El convento de mercedarios descalzos de Nuestra Señora de la Merced será uno de los elegidos por testadores con menor capacidad económica. Avanzando en la jerarquía social y adquisitiva de los testadores, los destinos elegidos son los franciscanos capuchinos de Santa Catalina Mártir y los carmelitas descalzos de Nuestra Señora del Carmen. 24 La cantidad acostumbrada que hemos constatado en el análisis de las disposiciones testamentarias ha sido para el siglo XVIII, la cantidad de 4 reales de vellón. No obstante, ya en el siglo XIX, hemos hallado documentos donde la cantidad estipulada para el pago de las misas por el alma de los testadores ascendía a 5 reales de vellón.(Nota de la autora). 
respecto de las iglesias parroquiales, lo cual tiene su correlación en las preferencias por los conventos de órdenes religiosas: franciscanos, dominicos, carmelitas descalzos y agustinos ${ }^{25}$. Es el caso de la otorgante, aunque pide ser enterrada en el cementerio de San José, no rehúsa a la celebración de misas por su alma en el convento de los descalzos de la ciudad.

A continuación, señala que su matrimonio tuvo lugar en La Coruña en 1780, al cual no aportó dote ${ }^{26}$ alguna. En cambio, su marido, le concedió una suma de 6.000 pesos fuertes, además las acostumbradas $\operatorname{arras}^{27}$ que ascendían a 4.000 pesos y numerosas alhajas de oro y brillantes. Los hijos del matrimonio fueron:

- Manuel, quien ha heredado el título de su difunto padre.

- María Teresa - María Javiera - María Fernanda

Nacieron dos hijos más, María Luisa y Luis Gonzaga, pero fallecieron durante la infancia.

La muerte de su esposo, José de Peralta, tuvo lugar en Cádiz el 24 de octubre de 1795, y ese mismo año los Señores Reyes ${ }^{28}$ le adjudicaron, en compensación de su estado de viudedad, y para sus gastos, la cantidad de 10.000 pesos, la mitad en vales reales, y el resto en efectivo. No obstante, la testadora manifiesta no haber recibido cantidad alguna hasta el momento, y que, en repetidas ocasiones ha hecho valer su derecho a percibir

25 DE LA PASCUA, M J.: Vivir la muerte en el Cádiz del setecientos, Fundación Municipal de Cultura. Exmo. Ayuntamiento de Cádiz, 1990. p.175. La autora constata en su obra, que será precisamente en la elección del hábito donde vayamos observando la sustitución de los franciscanos observantes por los de más estrecha observancia, fenómeno, que puede hablarnos de una voluntad de humildad aún mayor o, puede tener una explicación más simple: la saturación del convento de San Francisco Casa Grande, durante mucho tiempo el lugar de sepultura más concurrido. No obstante, serán las órdenes mendicantes las más asociadas con la muerte y con las ceremonias de culto fúnebre, ya que son las que asisten a entierros, presiden vigilias, facilitan mortajas..., por lo que no nos encontramos ante un fenómeno específicamente gaditano, sino más bien a una opción voluntaria más o menos condicionada por factores extradevocionales, pero encuadrada en un esquema de valores que parecía común a buena parte del mundo católico.

26 La dote consistía en el caudal que aportaba la novia al matrimonio, conformada generalmente de dinero y bienes raíces, y por el ajuar, compuesto por vestidos, alhajas, muebles, ropa de cama y utensilios necesarios para formar el nuevo hogar. De este modo, tanto la mujer como la institución del matrimonio se consideraban un instrumento de gran utilidad para establecer las conexiones parentales con el poder político, social y económico. Así, se convertía a la futura esposa en un sujeto determinante en las intrincadas relaciones entre linaje, poder, riqueza y honra, y a la dote, en el elemento vinculante por excelencia. Se convertía sí en un señuelo y fianza en el matrimonio, o capital de reserva del convento, siendo así la dote, elemento de ambición o marginación, de acuerdo con las posibilidades económicas de la familia. De hecho, si nos remontamos al Derecho Romano, la dote se tenía para medio de sustinere onera mantrimonii (sostener las cargas matrimoniales) convirtiendo a las mujeres en una sangría económica y un instrumento de gran utilidad para esablecer las conexiones parentales con el poder político, social y económico. En lo que se refiere al esposo, a la "Promesa de dote y ajuar", seguían las "arras o donación propter nupcias", consistente en un obsequio que este hacía a su futura esposa, en tributo a su virginidad y en los casos de nobleza, a su linaje. No siempre se entregaban en dinero efectivo, sino muchas veces en joyas o vestidos de elevado valor. En conclusión, el sentido del honor, las ansias de figuración y los gastos excesivos para mostrar una situación económica o social que a veces no era tal, significaron muchas veces un problema tanto para los padres que debían dotar a sus hijas, como para los novios que debían corresponder con arras a una dote por demás cuantiosa. En, SIEGRIST, N. / SAMUDIO A. EDDA O. (Coordinadoras): Dote matrimonial y redes de poder en el Antiguo Régimen en España e Hispanoamérica. Talleres Gráficos Universitarios. Universidad de los Andes. Mérida. 2006. pp. 26- 28.

27 Ibídem, op. cit. pp. 28- 29: A la Promesa de dote y ajuar, seguían las arras o donación propter nupcias, entregadas por el novio. Era un obsequio que este hacía a su futura esposa, en tributo a su virginidad y en los casos de la nobleza, a su linaje. Las arras no siempre se entregaban en dinero efectivo, sino muchas veces en joyas y vestidos de elevado valor.

28 Se refiere a Carlos IV y María Luisa de Parma, cuyo reinado se extendió entre 1788, cuando tiene lugar la muerte de Carlos III, y 1808, con la invasión francesa de la Península, la abdicación en su hijo Fernando VII y el comienzo de la Guerra de Independencia. 
lo que le fue concedido, apelando a la Junta Central Gubernativa ${ }^{29}$, cuya respuesta ha sido que: "cuando mejoren las actuales circunstancias ${ }^{30}$ se le reintegrará la cantidad estipulada".

Tal y como señalamos anteriormente, tiene puestos otros dos pleitos para la obtención de dos mayorazgos en nombre de su hijo. El primero de ellos, en Jerez de la Frontera con las religiosas de Nuestra Señora de la Merced. Este litigio se saldó de forma favorable para la testadora, según le remitió la Real Chancillería de Granada en 1803. El segundo, consiste en un mayorazgo sobre el marquesado navarro de Falces, que por herencia paterna le corresponde a su hijo. Se encuentra aún en vías de resolución en la Real Audiencia de Pamplona por estar la ciudad ocupada por los enemigos.

En las páginas finales del documento, es cuando la otorgante nos habla de sí misma, señalando expresamente: Habiendo fijado por la Misericordia de Dios mi domicilio en Cádiz después de tantos viajes, y de una vida tan agitada. A continuación, su última cláusula, en la que refiere vivir muy preocupada de que sus hijos hagan limosnas, ofrezcan sacrificios y apliquen limosnas por el alma de su padre y la suya propia. Pretende que continúen con el aniversario que ella misma viene realizando por el alma de su marido en la iglesia de las Descalzas de Cádiz. No obstante, deja claro, que no pretende que lo hagan por obligación, sino libremente, en virtud del afecto y amor que tuvieron a sus padres.

Para concluir, nombra como herederos universales a sus cuatro hijos, ratificando el título del marquesado en su único hijo varón, Manuel de Peralta Manrique de Lara.

Mostramos a continuación la Partición de bienes del Marqués de Casares, José de Peralta Manrique de Lara y Roelas, hecha por su esposa, Osoria Astrudi y Roelas ${ }^{31}$.

1.- El total del capital efectivo tras el fallecimiento del Marqués asciende a 98.468 pesos fuertes. La testadora ha aumentado esta fortuna con:

- 7.500 pesos que le fueron reintegrados en compensación a su viudedad a comienzos del año 1813.

- 7.655 pesos remitidos desde la ciudad de Lima en beneficio de la venta y arrendamientos de diferentes fincas que poseían en América.

-8.026 pesos en vales reales.

Todo ello suma la cantidad de 121.649 pesos fuertes, una auténtica fortuna para la época.

Declara que con esto ha logrado mantener a todos sus hijos con el decoro que les corresponde durante su viudez y minoría de edad.

2.- En lo que respecta a mobiliario de hogar perteneciente a la Marquesa hasta la fecha se refiere a las casas que tiene en diferentes ciudades de España:

$$
\begin{aligned}
& \text { 2.1.- Madrid: } \\
& \text { - una cómoda. }
\end{aligned}
$$

\footnotetext{
29 www.cervantesvirtual.com/portal/1812: En septiembre de 1808 se constituyó la Suprema Junta Central Gubernativa del Reino, que gobernaría en nombre de Fernando VII hasta su regreso, como depositaria de la soberanía que las distintas juntas le habían delegado.

30 Recordemos que estamos analizando un documento fechado en 1810, cuando aún no ha acabado el conflicto bélico, y las tropas francesas continúan en España.

31 AHPC. Sección de Protocolos Notariales. Libro 4621. Año de 1813.
} 
- un sofá pequeño.

- dos espejos ovalados.

- una urna de cristal con una maceta dentro.

- una imagen de La Dolorosa.

- un cuadro con un gato pintado en cristal.

- un espejo de tocador.

2.2 .- Granada:

- dos mesas de piedra.

- un catre de granadillo.

- un tibor ${ }^{32}$.

- diferentes libros, entre ellos un Año Christiano ${ }^{33}$.

2.3.- Cádiz:

- dos cómodas.

- dos sofás con almohadones de muselina.

- una mesa de piedra.

- una mesa de comedor.

- una mesa de cocina.

- un espejo de salón.

- once sillas estilo victoria ${ }^{34}$.

- ocho sillas de pasta.

- dos mesas de juego.

- catorce sillones compañeros de los sofás.

- una urna de cristal con tapadera.

- un cuadro de la Magdalena.

- un reloj de péndulo.

- un cuadro de San Roque.

- tres catres de respaldo.

- quince cuadros sin estampa de cristal.

- dos crucifijos de caoba.

- una figura de Nuestra Señora de los Dolores.

- cuatro cuadros pintados por sus hijas.

- ocho cuadros chicos.

- cuatro cuadros con la historia de Alejandro Magno.

- dos catres de lona.

- tres cuadros dorados sin cristal.

- seis cuadros dorados de salón con cristal.

32 Jarrón de origen oriental.

33 BARRIO MOYA, J. L.: "Objetos de oro y plata en la dote de la dama extremeña Doña Lucía de la Flor (1805)", en Coloquios Históricos de Extremadura. Archivo Histórico de Protocolos de Madrid. Protocolo: 21.004, folio. 220- 223. En la lista de objetos que conformaban dicha dote, se halla una biblioteca cuya temática era esencialmente cristiana. Entre las obras, destacaba un Año Cristiano, del jesuita francés Juan Croisset, y traducida del francés por el padre fray Juan Francisco Isla.

34 Se trata del tipo de mobiliario victoriano acostumbrado en la época, y que hace referencia al modelo inglés. En la isla británica, la soberana por antonomasia del siglo XIX fue la Reina Victoria, de ahí el apelativo de estilo victoria. 
- cuatro cuadros de Pío VI ${ }^{35}$.

- cinco cuadros chicos con cristal.

- una mesa de despacho.

- quince cortinas de Damasco.

- seis cortinas de seda.

- un cuadro de San Nicolás.

- ocho colchones.

- trece fundas de almohada.

- un cuadro dorado.

- un cuadro de la Concepción.

- una imagen del Niño Jesús dormido.

- una imagen de la Señora de las Angustias.

- cuatro cordones de seda para las cortinas monarca.

- tres cortinas de tafetán ${ }^{36}$ amarillo.

- dos colchas de muselina bordadas.

- una colcha de gasa.

- una colcha blanca.

- una colcha de León y otra de Damasco.

- una colcha de muselina listada.

- una colcha de muselina de Grecia.

- cuatro cortinas de colgadura.

- ocho visillos de muselina.

- una cortina de muselina bordada.

- una cortina bordada con flecos.

- dos almohadones de Grecia.

- dos almohadones bordados.

- sesenta y tres servilletas adamascadas ${ }^{37}$.

- siete tablas de manteles.

- diecisiete servilletas de cuadros.

- dos manteles de cuadros.

- veintiocho servilletas ordinarias.

- tres manteles ordinarios.

- diez servilletas de otra labor.

- cinco sábanas finas.

- siete sábanas ordinarias.

- treinta fundas blancas de almohada.

- seis fundas ordinarias de almohada.

- seis cobertores.

- seis almohadas de lienzo.

- doce visillos para vidrieras.

35 Se trata del último Papa que vivió el final del Antiguo Régimen, cuyo pontificado se extendió desde 1775 a 1799.

36 Se trata de un tejido de seda, formado de un cruzamiento de hilos pares de la urdimbre por un hilo de la trama y un cruzamiento de hilos impares de la urdimbre por otro hilo asimismo de la trama.

37 http://es.texsite.info/Tejido_adamascado: tela de doble selección gruesa y sedosa, de peso medio, con un rico estampado. La base del tejido es el satén, y el lino. Se utiliza con fines decorativos y como forro. 
- seis cortinas blancas.

- una cortina gorda de gabinete.

El patrimonio mobiliario asciende a un total de 1.536 pesos fuertes.

3.- En cuanto a las alhajas de plata, el documento refiere los siguientes objetos:

- Veinticuatro cubiertos compuestos de cuchara, tenedor y cuchillo de cabo negro.

- Tres docenas de platos, entre hondos y llanos.

- Una cuchara sopera.

- Una salvilla ${ }^{38}$.

- Seis candeleros.

- Doce cucharitas con concha y cabo de plata.

La cantidad de objetos en plata suponía un total de 952 pesos fuertes.

4.- Finalmente, encontramos una lista detallada de las propiedades y bienes muebles pertenecientes a la Marquesa y sus cuatro hijos:

- Un cortijo en Huétor Tájar, Granada, con un valor de 114. 000 pesos fuertes.

- Una casa llamada Molino de Aceite de Linaza, en Pinos Puente, Granada, valorada en 44.000 pesos.

- Un haza ${ }^{39}$ de tierra de ocho marjales ${ }^{40}$ de tierra en el Zaidín; otra de 11 marjales; otra más de 12; y una última de 7 marjales. Todas ellas en el mismo lugar.

- Un cortijo llamado Herrera, en la villa de Iznájar, en el término de Granada, que ascendía a 2.639 pesos fuertes.

- Un cortijo que llevaba por nombre Escaruela, también en el término de Granada, valorado en 5.250 pesos.

- Un cortijo pequeño de 25 marjales de tierra de riego en el Zaidín, de 1.720 pesos fuertes.

El total de propiedades ascendía a un total de 19.104 pesos fuertes.

Para concluir, nos gustaría destacar, tal y como planteamos al comienzo del artículo, el papel determinante que estas mujeres jugaron en su vida diaria, asumiendo roles decisorios en los negocios familiares, heredados de los esposos fallecidos. Tanto es así que en los últimos años del siglo XVIII, y principios del XIX, en Cádiz, la mujer, especialmente de la élite, había incrementado de forma notable su autonomía y su influencia en la vida pública y privada. Numerosas esposas y viudas de comerciantes habían aprendido a plantear y resolver sus asuntos financieros y legales con los hombres de dentro y fuera de su hogar ${ }^{41}$.

Al hilo de esta cuestión, no queremos dejar pasar la ocasión de señalar que existen diferentes hipótesis que han formulado la idea de que para ciudades marítimas, como el

38 Bandeja con una o varias encajaduras donde se aseguran las copas.

39 Porción de tierra dedicada a la labranza.

40 Una antigua medida agraria correspondiente a unos 528 metros cuadrados. El marjal es aún, en la Vega de Granada, también en las de Motril y Guadix, la unidad de medida de superficie normalmente utilizada en todo tipo de transacciones agrarias, y equivale exactamente a la superficie del Patio de los Leones de la Alhambra: $528,42 \mathrm{~m}^{2}$. (Nota de la autora).

41 PÉREZ FERNÁNDEZ, P.: El rostro familiar de la metrópoli., p. 239. 
caso de Cádiz, situadas en la encrucijada de rutas internacionales de comercio, atrajeron en la época moderna numerosos individuos, pero también expulsaron de forma temporal o permanente a gran cantidad de hombres inmersos en el mundo mercantil y de negocios de la Carrera de Indias. Estos movimientos estacionales, fundamentalmente de varones, crearon una organización del hogar en la que la mujer tenía un peso considerable, y una situación de quiebra familiar en la que ésta debió afrontar problemas que normalmente habrían resuelto los hombres en zonas y épocas de mayor sedentarismo profesional ${ }^{42}$.

Tal y como hemos analizado en nuestro trabajo, las viudas de estos hombres de negocios, habían pasado a formar parte activa del entramado comercial y administrativo de la ciudad, encargándose de los asuntos y dependencias de sus difuntos esposos. El testamento de María Osoria Astraudi, es un ejemplo en el que constatamos cómo esta mujer vuelca todo su esfuerzo en continuar con la buena marcha de los negocios de su marido, "mejorando" y ampliando la fortuna heredada tras el fallecimiento del marqués. Semejantes iniciativas de autoridad y decisión encontramos en la disposición de Manuela Bustillo, donde además queda patente la independencia económica y la libre disposición del patrimonio del que se hace gala en sus adjudicaciones de bienes.

Respecto a las relaciones afectivas, especialmente las materno filiales, son evidentes en estas disposiciones, en especial, el caso de la Marquesa de Casares, donde la búsqueda del bienestar y felicidad de sus hijos, es el interés primordial de la testadora.

No obstante, estas relaciones de carácter afectivo, se hacen más notables con respecto a las mujeres que formaban parte de la vida de las otorgantes. De hecho, la protección hacia el elemento femenino y desvalido, en el caso de hijas, hermanas, sobrinas o ahijadas, como hemos analizado en la disposición de Manuela Bustillo, se convierte en una estrategia para asegurar la supervivencia y el amparo de quienes comenzaban a tomar conciencia de su verdadero papel en la sociedad de la época.

42 PÉREZ FERNÁNDEZ, P.: El rostro familiar de la metrópoli., p. 239. 